\title{
Controlled Cracking of Large Size Concrete Structures by a Steam Pressure Cracking Agent
}

\author{
Osamu Kamiya ${ }^{1}$, Kaito Suzuki ${ }^{1}$, Etsushi Okuyama ${ }^{1}$, Naoya Kojima ${ }^{1}$, Jyunpei Nanao ${ }^{2}$, \\ Shinichi Ito ${ }^{1}$, Mamoru Takahashi ${ }^{1}$, Yasuyuki Miyano ${ }^{1}$, Kenji Murata ${ }^{3}$, Takashi Kazumi ${ }^{3}$, \\ Arata Maisawa ${ }^{3}$, Masanobu Nakatsu ${ }^{4}$, Hiroyuki Mizuma ${ }^{4}$, Yuichi Iwama ${ }^{4}$ \\ 1. Department of System Design Engineering, Faculty of Engineering Science, Akita University, Akita 010-8502, \\ Japan \\ 2. Department of Earth Resource Engineering and Environmental Science, Faculty of International Resource \\ Science, Akita University, Akita 010-8502, Japan \\ 3. Research \& Development Department, Nippon Koki Co., Ltd., Fukushima 961-8686, Japan \\ 4. Sanwa Tekki Corporation, 6-4-6 Minami-Shinagawa, Shinagawa-ku, Tokyo 140-8669, Japan \\ E-mail: kamiya@gipc.akita-u.ac.jp
}

Received: 11 December 2020; Accepted: 6 January 2021; Available online: 25 February 2021

\begin{abstract}
The dismantling of large concrete structures causes environmental pollution due to the dispersion of polluted micro-particles. The purpose of this study is to develop an environmentally friendly demolition method. Steam pressure cracking (SPC) is a method that can safely and quickly separate concrete because there is less vibration compared to the explosion method. To date, the authors have shown that the direction of cracking in a small sample can be controlled by an induction hole. The principle of control is that the elastic wave of compression stress generated from the SPC reaction changes to a tensile elastic wave at the induction hole, and a crack is initiated. In this study, it was shown that the direction of crack propagation can be controlled by using induction holes in large concrete structures that are $1 \mathrm{~m}$ on each side. Further, in the SPC method, the large amount of concrete powder generated by the explosion method is not produced, and there is no risk of secondary contamination by fine concrete powder. It was also possible to separate small pieces from the end face of the large concrete by SPC and induction holes. The area over which the crack propagated depends on the energy generated from the SPC agent, and the relationship was linear. By applying an SPC agent to dismantling large concrete structures, we can achieve controlled cracking safely and quickly without any environmental pollution.

Keywords: Controlled cracking; Steam pressure cracking agent; Large concrete; Induction hole; Elastic wave; Surface energy.
\end{abstract}

\section{Introduction}

Dismantling of large concrete structures causes environmental pollution. The purpose of this study is to develop a demolition method that does not cause environmental problems. Therefore, the authors focus on the separation method using steam pressure cracking (SPC) $[1,2]$ which has advantages over conventional concrete cracking methods such as rapid, safe, and controlled crack propagation [3]. In this study, the crack propagation mechanism and controlled cracking characteristics of large concrete structures by an SPC agent were elucidated using both theoretical and experimental analysis.

Concrete structures that can no longer be used due to disasters have become a social problem [4-6] and require safe and urgent dismantling. There are three methods for dismantling large concrete structures that have been previously utilized. The first is a blasting method that uses explosives such as dynamite [7-12]. In addition, a hydraulic rock splitting method that uses a hydraulic cracking machine and a static crushing method that uses nonexplosive demolition agents $[13,14]$ that are expanded by a hydration reaction have also been used.

Initially, dynamite containing nitroglycerine was used for blasting. However, dynamite is not currently produced in Japan. Currently, "slurry or emulsion explosives", which are safer than dynamite, are used for blasting. Using this method, the size of the object to be demolished is limited because the explosion is accompanied by a large shock wave, vibrations, scattering of objects, and high-temperature gas spouting, which can adversely affect 
the surroundings. Furthermore, the handling of explosives must be authorized by an administrative official, and therefore, they cannot be used urgently in the event of a disaster.

The hydraulic split rock method allows concrete to be demolished quietly because there is no explosive sound. On the other hand, because this method uses a large heavy machine called a hydraulic rock split machine, the disadvantage is that it cannot be done without sufficient preparation time, size, and scaffolding.

To crush concrete using a "static crusher agent" the agent is poured into a hole, and the expansion pressure generated when it reacts and expands creates a crack in the concrete $[13,14]$. The static crusher agent is defined as a non-explosive demolition agent, thus worker safety is ensured. However, a disadvantage of this method is that it can take a long time for the expansion pressure to increase and a crack to occur in the object. Depending on the product, this may take up to 24 hours, so it cannot be used for emergency measures.

Therefore, in this study, to solve the problems of the conventional method, we developed a controlled cracking method that uses an SPC agent. SPC agents are safe chemicals that are also used to inflate car airbags. In this study, we showed that this agent can be used to quickly crush large amounts concrete by controlling the cracking direction.

\section{Experimental methods}

\subsection{Concrete test materials}

The typical concrete used in the experiment was cured for more than 3 weeks by mixing cement, sand, gravel, and water with a volume ratio of 1:2:4:0.5 into the mould.

The material properties of the concrete are listed in Table 1. Because the compressive strength of concrete used in this study varies widely, compression tests could not be performed on all test pieces. Therefore, we used a Schmidt hammer $[15,16]$ to measure the Schmidt value of the concrete surface, which is then converted into a compressive strength of $\sigma_{c \text {. }}$ by equation (1) [16].

$$
\sigma_{c}=0.9294 x-1.1219 \quad\left[\mathrm{~N} / \mathrm{mm}^{2}\right][16]
$$

The shape of the concrete used for the crushing test is shown in Figure 1 (a) and (b).

Table 1. Nominal material properties of concrete used

\begin{tabular}{lcc}
\hline Material properties & Value & {$[\mathrm{unit}]$} \\
\hline Compressive Strength, $\sigma_{\mathrm{c}}$ & $20 \sim 50$ & {$\left[\mathrm{~N} / \mathrm{mm}^{2}\right]$} \\
Tensile strength, $\sigma_{\mathrm{t}}[17]$ & $\left|\sigma_{\mathrm{t}}\right|<\left|\sigma_{\mathrm{c}} / 10\right|$ & {$\left[\mathrm{N} / \mathrm{mm}^{2}\right]$} \\
Density, $\rho$ & $2.3 \sim 2.5$ & {$\left[\mathrm{~g} / \mathrm{cm}^{3}\right]$} \\
Elastic Modulus, E & $10 \sim 50$ & {$[\mathrm{GPa}]$} \\
Schmidt values & $10 \sim 60$ & {$[\mathrm{R}]$} \\
Velocity of elastic wave & $4500 \sim 5400$ & {$[\mathrm{~m} / \mathrm{s}]$} \\
\hline
\end{tabular}

* Values measured by the authors
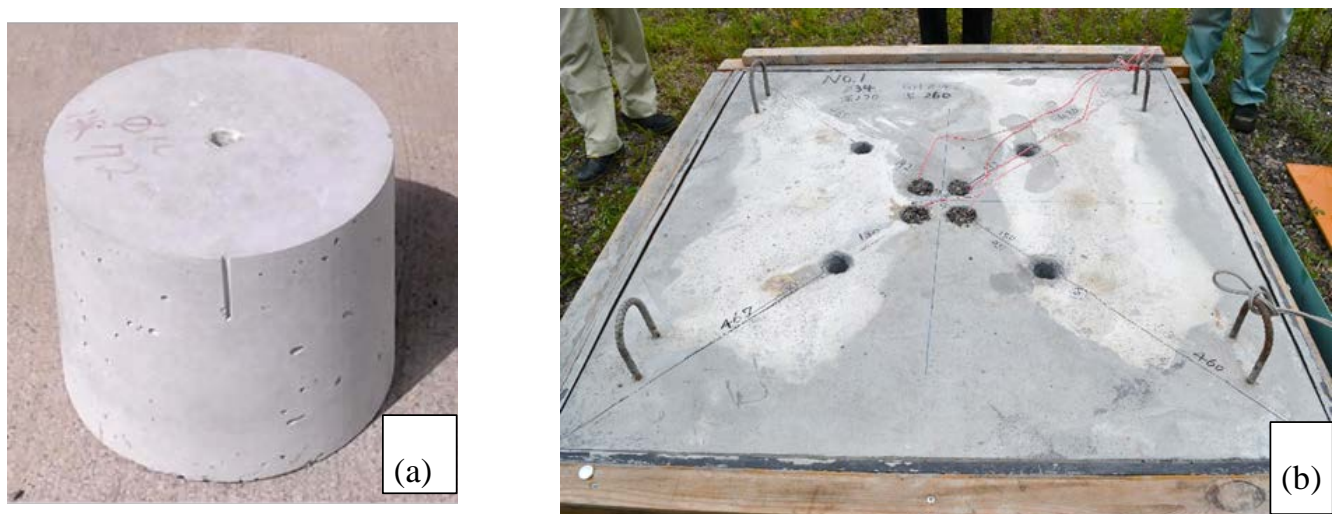

Figure 1. Concrete size used; (a) small type, Cylinder; $\Phi 150 \times 150 \mathrm{~mm}$, (b) large type, Beam; $1000 \times 1000 \times 500 \mathrm{~mm}$.

\subsection{Characteristics of the SPC agent}

The chemical composition of the SPC agent used in the experiment is shown in Table 2, and the physical properties are listed in Table 3. 
Table 2. Chemical composition of the steam pressure cracking (SPC) agent

\begin{tabular}{lc}
\hline Composition materials & Mass \% \\
\hline Alum $\left(\mathrm{nKAl}\left(\mathrm{SO}_{4}\right)_{2} 12 \cdot \mathrm{H}_{2} \mathrm{O}\right)$ & 50 \\
Copper $(\mathrm{II})$ oxide $(\mathrm{CuO})$ & 38 \\
Al fine powder & 11 \\
Binder & 1.0 \\
\hline
\end{tabular}

Table 3. Physical properties of agent used

Ignition point

Reaction speed

Rise time to maximum pressure

Sealed combustion pressure

Volume of gas produced

Theoretical energy product with standard mixture
$793 \mathrm{~K}\left(520^{\circ} \mathrm{C}\right)$ or higher

Less than $300[\mathrm{~m} / \mathrm{s}]$

$30 \sim 50\left[10^{-3} \mathrm{~s}\right]$

$300 \mathrm{MPa}$

$330 \mathrm{l} / \mathrm{kg}$

$1170 \mathrm{~kJ} / \mathrm{kg}$

The agent is ignited by inserting an appropriate amount into the centre of the concrete and heating it to 793 $\mathrm{K}\left(520^{\circ} \mathrm{C}\right)$ using the igniter. The agent causes the reaction shown in equation (2), which creates water and heat. The water evaporates in a short time, and then the concrete is crushed by the high-pressure steam and elastic waves generated by it as shown in Figure 2.

$$
2 \mathrm{Al}+\frac{9}{2} \mathrm{CuO}+\mathrm{nKAl}\left(\mathrm{SO}_{4}\right)_{2} \cdot 12 \mathrm{H}_{2} \mathrm{O} \rightarrow \frac{3}{2} \mathrm{Al}_{2} \mathrm{O}_{3}+\frac{9}{4} \mathrm{Cu}_{2} \mathrm{O}+\mathrm{nKAl}\left(\mathrm{SO}_{4}\right)_{2}+12 \mathrm{nH}_{2} \mathrm{O} \uparrow+1170 \mathrm{~kJ} / \mathrm{kg}[2]
$$
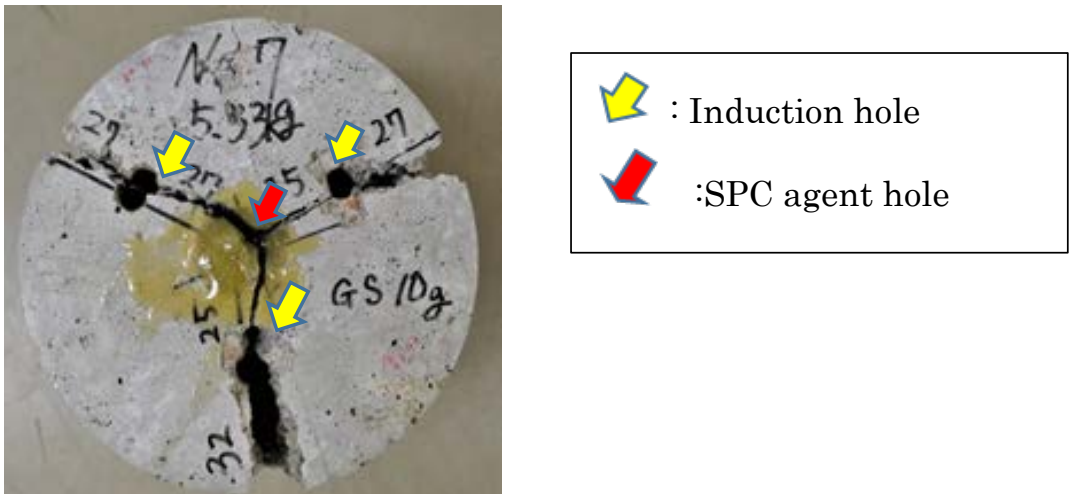

Figure 2. Controlled cracking of a small concrete piece by the SPC agent [3].

\subsection{Large sample crushing test}

In this test, we examined whether induction holes are effective for controlling cracking using large samples, assuming actual structures. Test methods and results in small samples were shown in a previous report [3]. A large rectangular test sample was provided with an agent treatment hole at the centre, and an induction hole was perforated diagonally. When the induction hole affects the cracking behaviour, the crack occurs diagonally, and if there is no induction hole, it is predicted that a crack will occur in a cross shape along the shortest distance. The crushing test was carried out under normal atmospheric conditions, and a poly bucket containing water was installed on the sample to prevent the steam from leaking out above. Figure 3 illustrates the method used to insert the SPC agent into a large concrete test piece. The total amount of SPC agent was divided into four parts of $60 \mathrm{~g}$ each that were loaded into the central borehole, for a total of $240 \mathrm{~g}$ as shown in Table 4.

Table 4. Cracking conditions

\begin{tabular}{cc}
\hline SPC hole $\Phi \times$ depth [mm] & $\Phi 34 \times 270$ \\
Induction holes $\Phi \times$ depth [mm] & $\Phi 34 \times 260$ \\
Amount of SPC [g] & $240(60 \mathrm{~g} \times 4$ pieces $)$ \\
Concrete size [mm] & D $1000 \times$ W $1000 \times$ H500 \\
Schmidt hammer value [R] & 61 \\
Cracking condition & In air, Caver on the SPC hole \\
\hline
\end{tabular}



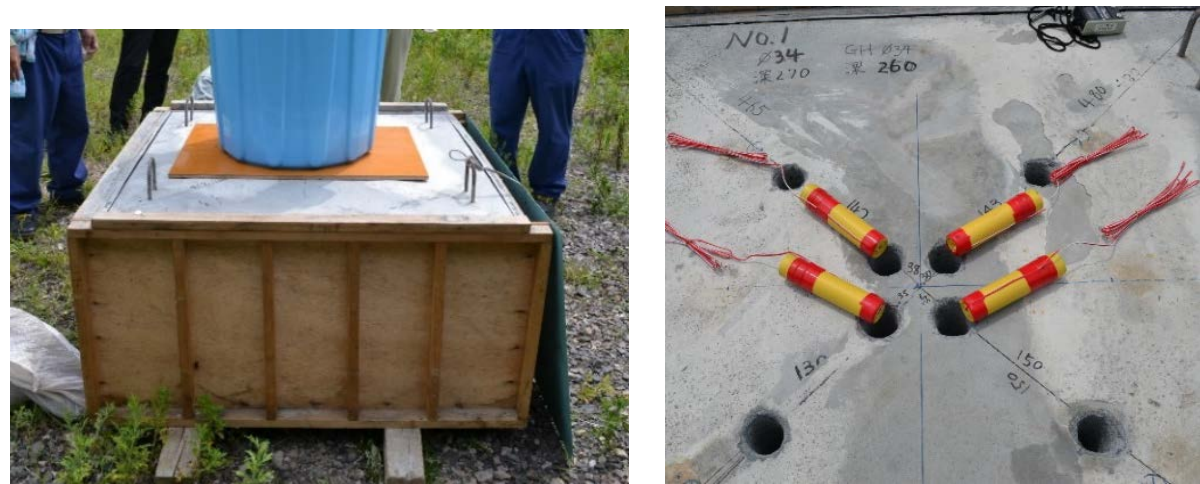

Figure 3. SPC agent insertion into large concrete test pieces

\section{Crushing results and discussion}

\subsection{Crushing results of large concrete sample}

The results of the crushing test are shown in Figure 4. Cracking occurred in three directions. The cracks shown in (2) and (3) in the figure occurred diagonally along the induction holes. Crack (1) did not pass through the open induction hole, but a crack occurred along induction hole (4) that filled with mortar and closed. Therefore, it can be said that the induction hole method is effective even in a large concrete sample close to the actual structure, and the crack can be controlled. It was also shown that the induction holes that were closer had the biggest impact, whether open or closed, on crack propagation. It is considered that a hole loaded with mortar also has the same effect as an induction hole. For this reason, it can be inferred that a pseudo boundary surface, in which the mortar cannot be fully joined, is formed by loading the hole once it is perforated with a different material. It is thought that the compressive elastic wave is reflected at the pseudo-boundary surface as well as the free surface and becomes a tensile stress wave.

In addition, it was found that the steel rebar (5) contained in the concrete sample used in this test can be cut at the same time. The reaction time of the SPC agent was short, and the steel rebar was subjected to impact pulling and cut with little elongation.

In the previous test, the entire sample was crushed by installing an SPC agent hole in the centre of the concrete specimen. Here, the concrete was partially chipped off from the end surface of the test piece. In actual construction, there are many so-called chipping constructions that partially separate concrete blocks. Previously, impact tests of concrete using mechanical systems have been conducted [18-20], but there are no examples of controlling the propagation direction of the crack.

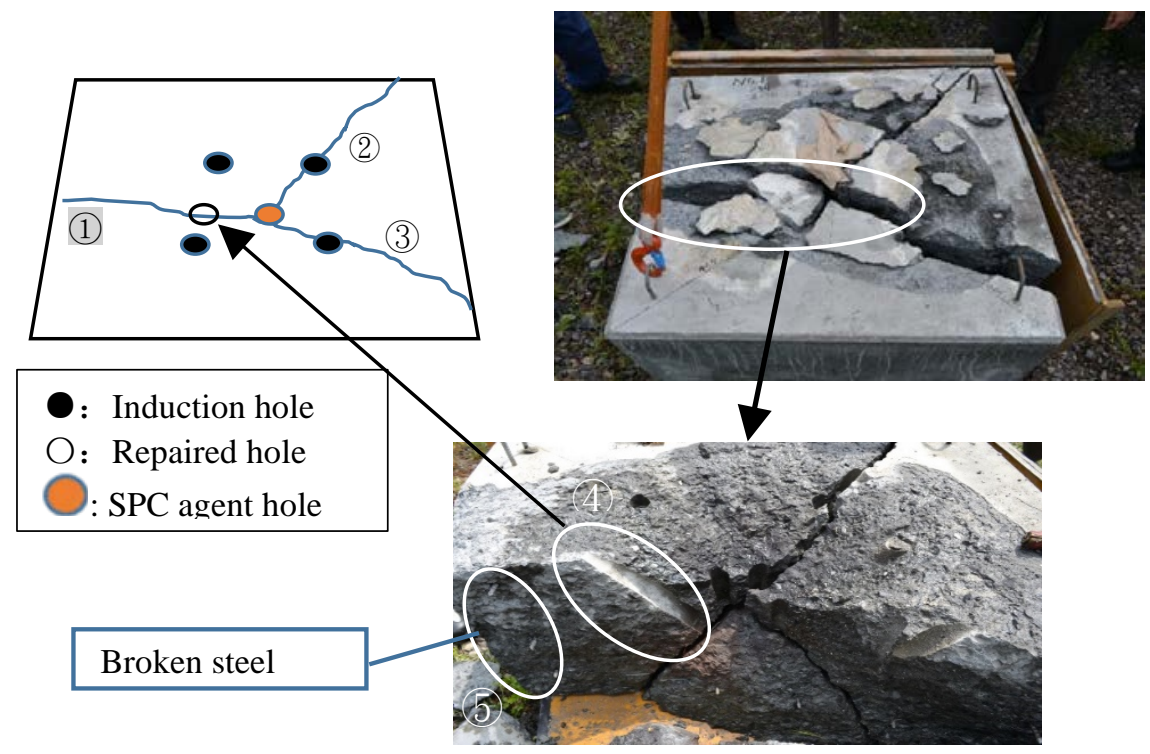

Figure 4. Concrete cracked by SPC agent 
Figure 5 shows the results of the chipping test carried on the cracking conditions of Table 5. Cracking occurred from the repair hole without passing through the induction hole, and it was crushed into a T-shape. This is an ideal form for chipping. The reason why the crack does not pass through the induction hole is that the generated propagation of the crack is caused not by static stress concentration, but by the tensile stress due to the reflected elastic wave at the induction hole interface.

In addition, Figure 5 indicates that it is difficult to induce a tear between induction holes when multiple induction holes are not installed coaxially from the SPC agent hole, as shown in Figure 5.

Table 5. Cracking conditions of the chipping test

\begin{tabular}{cc}
\hline SPC hole $\Phi \times$ depth [mm] & $\Phi 34 \times 310$ \\
Induction holes $\Phi \times$ depth [mm] & $\Phi 34 \times 310$ \\
Amount of SPC [g] & $120 \mathrm{~g}(60 \mathrm{~g} \times 2$ holes $)$ \\
Concrete size [mm] & D $1000 \times$ W $1000 \times \mathrm{H} 500$ \\
Schmidt hammer value [R] & 61 \\
Cracking condition & In air \\
\hline
\end{tabular}
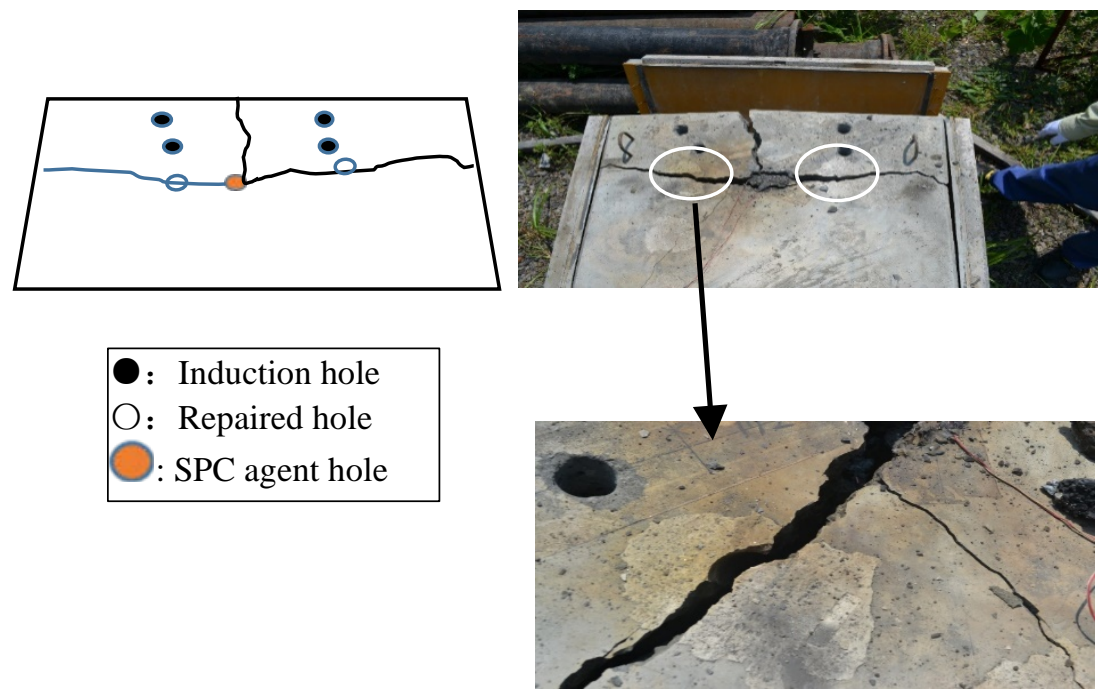

Figure 5. Concrete chipped by SPC

\subsection{Elastic wave propagation and cracking}

The controlled cracking phenomenon schematically shown using the elastic wave theory in Figure 6, which indicates the arrangement of the SPC and the induction hole, as well as the propagation and reflection of elastic waves in large concrete.
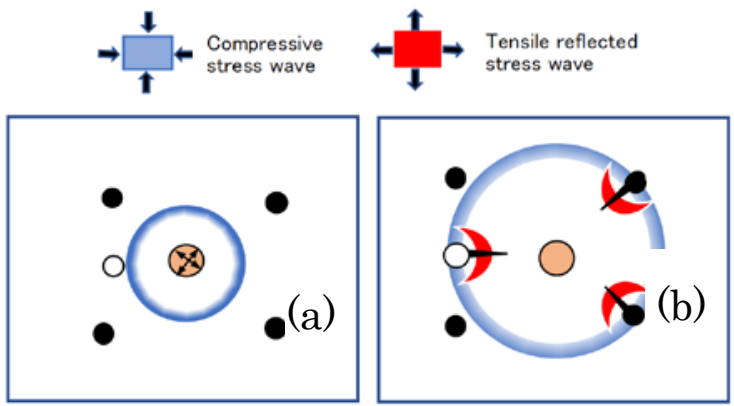

: Induction hole

O: Repaired hole

: SPC agent hole

: Cracking

Figure 6. Schematic figure of tested concrete that shows the SPC agent, induction hole and repaired hole. The elastic wave initiates from the SPC in Figure 6(a) and reflects at the induction hole shown in Figure 6(b). Areas of compressive stress are shown in blue, and red areas represent tensile stress. 
The SPC cracking phenomena are based on three-dimensional elastic wave propagation; however, to understand the phenomena, the authors used the following equation, which is a one-dimensional elastic wave equation [21]:

$$
\frac{\partial^{2} u(x, t)}{\partial t^{2}}-v^{2} \frac{\partial^{2} u(x, t)}{\partial x^{2}}=0
$$

where $u$ is the displacement produced by SPC, $v$ is the velocity of the elastic wave, $x$ is the distance from the induction hole surface, $t$ is the time, and $v=\sqrt{E / \rho}$ (E:Young's modulus, $\rho$ : density of concrete) in an elastic solid. Concrete is considered a composite elastic solid composed of sand, aggregate, and cement, and has homogeneous E and $\rho$.

Longitudinal elastic waves are generated by the reaction of the SPC agent. As a general solution of equation (3), the following d'Alembert equation is given as:

$$
u(x, t)=f(x-v t)+g(x+v t)
$$

where $f(s)$, and $g(s)$ are arbitrary functions that correspond to the "driving wave" and the "reflected wave", respectively. Equation (4) can be confirmed to be the correct solution when attempting to substitute equation (3) [21].

The functions $f(s)$ and $g(s)$ indicate the displacement of elastic waves that move in opposite directions at speeds of $+v t$ and $-v t$, respectively. The driving wave $f(s)$ is related to the reflected wave $g(s)$ at the free surface of the induction hole as follows [21]:

$$
f(-s)=g(s)
$$

The shapes of $f(s)$ and $g(s)$ correspond to the actual elastic wave that is generated by the SPC compressive pressure and can use the Gaussian functions or the wave packet. The peak value corresponds to the maximum pressure of the SPC agent, which is approximately $300 \mathrm{MPa}$,and the time spread is approximately 50 [10 $\left.0^{-3} \mathrm{~s}\right]$. In the future, we would like to determine the elastic wave function form of the SPC agent after measuring accurate data.

The stress $\sigma$ of the elastic body produced by displacement $u$ is expressed by the following equation:

$$
\sigma(x, t)=E \cdot u^{\prime}(x, t)
$$

where $u^{\prime}(x, t)$ is the value of the partial deviations for $x$.

$$
\sigma(x, t)=E \cdot f^{\prime}(x-v t)+E \cdot g^{\prime}(x+v t)
$$

Considering $x=0, \sigma=0$ at free surface of the induction hole, as shown in Figure 6.

$$
\begin{aligned}
& u^{\prime}(x, t)=f^{\prime}(-v t)+g^{\prime}(v t)=0 \\
& f^{\prime}(-v t)=-g^{\prime}(v t)
\end{aligned}
$$

Equation (6) indicates that the stress of the driving wave $\sigma=E \cdot f^{\prime}(-v t)$ is compressive; however, the pressure of the reflected wave $\sigma=-E \cdot g^{\prime}(v t)$ is tensile stress. These phenomena are known as the Hopkinson effect, which is applied for dynamic testing [18]. However, no example has been found for controlled cracking in concrete.

The magnitude of the stress $\sigma$ is dependent on $u^{\prime}(x, t)$ instead of $u(x, t)$, which means that the stress is not related to the maximum pressure but to the gradient of displacement. In other words, the level of $\sigma$ depends on the speed of the reaction of each chemical agent. The maximum compression pressure of the SPC agent at the centre is approximately $3,000 \mathrm{kgf} / \mathrm{cm}^{2}(\fallingdotseq 300 \mathrm{MPa})$, and the time scale is approximately $100\left[10^{-3} \mathrm{~s}\right]$. However, the explosive pressure is high (10 GPa), and the time scale is small $(100 \mu \mathrm{s})$. The slower reaction times enable the SPC agent to control the cracking of the concrete. The authors propose a cracking control condition by using the induction hole,

$$
\begin{gathered}
\sigma_{c D}=E \cdot f^{\prime}(x-v t)<\sigma_{c} \\
\sigma_{t R}=-E \cdot g^{\prime}(x+v t)>\sigma_{t}
\end{gathered}
$$


where $\sigma_{c D}$ is the maximum compressive stress of the driving elastic wave, $\sigma_{c}$ is the compressive strength of the concrete used, $\sigma_{t R}$ is the maximum tensile stress of reflected elastic wave near induction hole, and $\sigma_{t}$ is the tensile strength of the concrete used.

The authors estimated the values of $\sigma_{c}$ and $\sigma_{t}$ as - $55 \mathrm{MPa}$ and $5.5 \mathrm{MPa}$, respectively, in this study.

The functions $f^{\prime}(x-v t)$ and $g^{\prime}(x+v t)$ have dimensions of strain, and the values are related to the reaction speed of the explosive agent. We can analyse the critical values of $f^{\prime}(x-v t)$ by substituting the data given in Table 1.

$$
\begin{aligned}
& f^{\prime}(x-v t)<\sigma_{c} / E=-55 / 30000=-0.18 \% \\
& g^{\prime}(x+v t)<\sigma_{t} / E=5.5 / 30000=0.018 \%
\end{aligned}
$$

Therefore, to design controlled cracking, it is essential first to select an SPC that has an appropriate reaction speed according to the strength of the target material. The values of the displacement gradient of concrete cannot be obtained by analytical methods but only by experiments. The authors are applying the results of this research to develop a controlled cracking mechanical system for concrete.

\subsection{Impact fracture toughness of concrete}

The authors consider that the size of the induction hole required to control the tear propagation is related to the fracture toughness value of the concrete. That is, when the Diameter $d$ of the induction hole is set, it is assumed that the Crack length $a_{c}$ generated is expressed by the following formula:

$$
a_{c}=k d
$$

where $k$ is an experimental constant. If the fracture toughness value of concrete is expressed as $K_{\text {I } c c}$ and the tensile stress of the reflected wave is $\sigma_{t}$, the following equation consists of:

$$
\begin{aligned}
& K_{\mathrm{I} c c}=\sigma_{t} \sqrt{\pi a_{c}}=\sigma_{t} \sqrt{\pi k d} \\
& d=\frac{{ }_{\mathrm{I} c c}{ }^{2}}{\sigma_{t}{ }^{2} \pi k}
\end{aligned}
$$

Therefore, the size of the induction hole must be greater than the value of the above equation. In addition, the size is determined by the vapour pressure and distance to the induction hole.

The relationship between the fracture surface area of concrete and the energy possessed by the SPC agent was investigated. If the amount of SPC agent can be estimated before the actual construction, the agent can be conserved. Table 6 and Figure 7 show the results of the large concrete sample tested in this study and the test

\begin{tabular}{|c|c|c|c|c|}
\hline Concrete size [mm] & $\begin{array}{l}\text { SPC agent mass [g] } \\
{[\mathrm{kJ}]}\end{array}$ & $\begin{array}{c}\text { SPC agent } \\
\text { Energy }[\mathrm{kJ}]\end{array}$ & $\begin{array}{c}\text { Crack number } \\
{[\mathrm{n}]}\end{array}$ & $\begin{array}{l}\text { Crack } \\
\text { area }\left[\mathrm{m}^{2}\right]\end{array}$ \\
\hline \multirow[t]{2}{*}{ Cylinder- $\Phi 150 \times 150$} & 5 & 5.85 & 2 & 0.0225 \\
\hline & 10 & 11.7 & 3 & 0.0338 \\
\hline Beam-300×300×200 & 40 & 46.8 & 3 & 0.126 \\
\hline \multirow{2}{*}{ Beam-300×300×300 } & 60 & 70.2 & 3 & 0.189 \\
\hline & 60 & 70.2 & 4 & 0.18 \\
\hline \multirow[t]{2}{*}{ Beam- $000 \times 1000 \times 500$} & 120 & 140.4 & 3 & 0.65 \\
\hline & 240 & 280.8 & 3 & 0.95 \\
\hline
\end{tabular}
pieces of various sizes that have been examined so far. The author considers that there is some relationship between the crack area and the SPC amount because the crack propagation energy is only produced by chemical reaction of the SPC agent.

Table 6. SPC agent mass

Based on the fracture mechanics, it can be said that the internal strain energy is released by forming a fracture surface. The pressure energy caused by the SPC agent is converted to strain energy, W, which is called the elastic wave, and W is released by crack propagation of length, c. In other words, it is thought that energy is absorbed or exhausted when forming a fracture surface. Fractures can be thought of as the surface energy $\gamma$ of the fracture surface. This is expressed in the following formula: 


$$
W=2 c \gamma
$$

where $\mathrm{W}$ is the total strain energy corresponding to the energy of the SPC agent, $\mathrm{c}$ is the crack length corresponding to the area of the fracture surface, and $\gamma$ is the surface energy as a material constant of the concrete used.

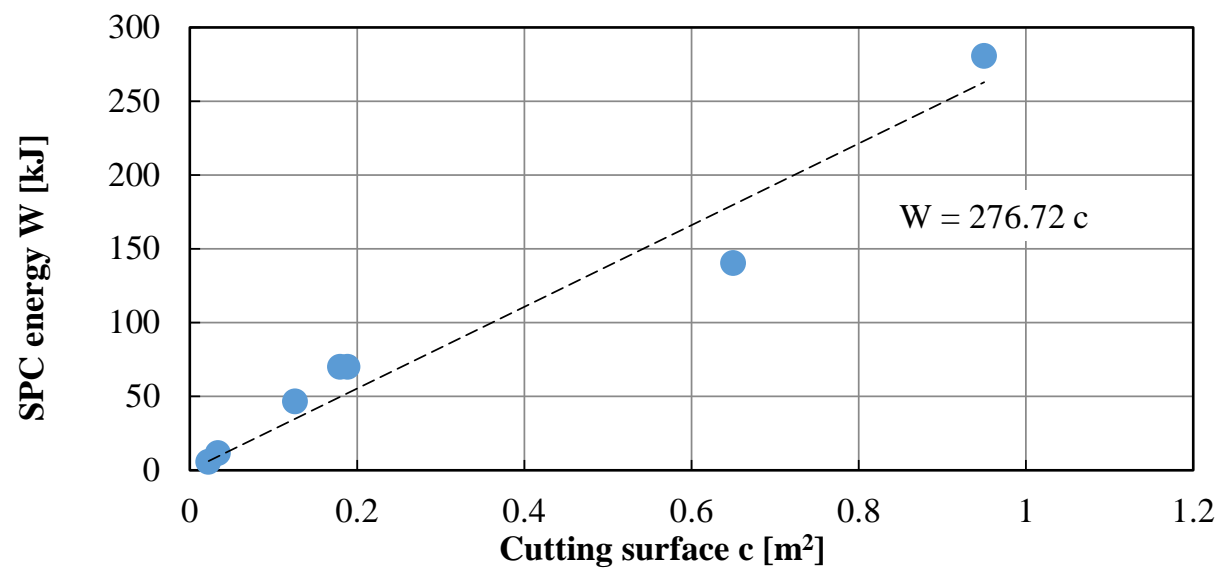

Figure 7. Amount of energy generated and cross-sectional area

However, the conversion rate from pressure energy to elastic strain energy varies depending on the reaction conditions of the SPC agent. If the SPC agent is released, the energy of the reaction gas is released into the atmosphere as adiabatic expansion. When ideal sealing of the SPC agent is carried out, the total energy of the elastic wave is proportional to the amount of the agent used. Therefore, it should be possible to infer the amount of SPC agent required from the fracture area of concrete.

The differential value of equation (16) with respect to $c$ is called the energy release rate.

$$
\frac{d W}{d c}=2 \gamma
$$

A high value indicates that the concrete is less likely to crack, so this is usually called the fracture toughness value. In other words, concrete with a large surface energy is hard to crack. From this point of view, it can be said that concrete that absorbs energy by generating a secondary tear at the crack tip is less likely to crack. Improving the accuracy of the steam pressure crushing test and accurately measuring the relationship between energy and fracture area can contribute to the development of concrete with a high impact toughness value, which will make it resistant to impact crushing.

\section{Conclusion}

In this study, we examined a method for controlling the crushing of concrete using an SPC agent. By using an induction hole, it is possible to control the direction of the generated crack, and cracking control using induction holes were effective even in the case of a large sample of the size used for construction.

1) Using a SPA agent that generated high-pressure steam, it was possible to crush concrete more safely than explosives and without generating dust.

2) By using an induction hole, the direction of the generated tear could be effectively controlled.

3) From the theory of elastic waves, it was shown that the principle of crack control is due to the tension stress of the reflected wave from the induction hole.

4) The concrete fracture surface area depended on the generated energy of the SPC agent, and a proportional relationship was established.

5) From the relationship between the fracture surface area and energy, the impact toughness value of concrete can be estimated.

It is expected that this will contribute to the development of concrete that is resistant to impact loads in the future through experiments using vapour pressure crushers for controlled fracturing.

\section{Acknowledgment}

We would like to thank Nippon Koki Co., Ltd. and SANWA TEKKI CORPORATION for providing the 
experimental facilities and their technical support. We would also like to thank Editage (https://www.editage.jp/) for English language editing.

\section{References}

[1] Japanese Ministry of Land, Infrastructure,Transport and Tourism. Steam pressure cracking agent IC igniter. New Technology Information System (NETIS). 2021; (No. KT-190005-A).

[2] Nippon Koki Co., LTD. Product specifications of GANSIZER. 2020. https://www.nippon-kokimarketing.com /en/products/gansizer/spec.html.

[3] Kamiya O, Suzuki K, Kojima N, Ito S, Takahashi M, Murata K, Kazumi T, Misawa A, Mizuma MNH, Sodeyama H, Iwama Y, Furuuchi N, Shinya K. Controlled cracking for industrial concrete waste by steam pressure cracking agent. International Journal of the Society of Materials Engineering for Resources. 2020; 24(1/2): 18-22.

[4] United Nations. Transforming our world: the 2030 agenda for sustainable development. General assembly (SDG's). 2015.

[5] Shimada T, Ohshima S, Sukegawa T. Development of safety assessment code for decommissioning of nuclear facilities. Journal of Power and Energy Systems. 2010;4(1): 40-53.

[6] Iguchi Y, Yanagihara S. Integration of knowledge management system for the decommissioning of nuclear facilities. Mechanical Engineering Journal, 2016;3(3): 15-00518.

[7] Ito I, Sassa K, Tanimoto C. Mechanism of rock breakage under pressure of gas explosion. Journal of the Society of Materials Science, Japan. The Society of Materials Science. 1971;20(209): 203-208.

[8] Li PW, Wei SC, Chih MC, Murata K, Fujita T. Applying underwater explosion for the liberation of neodymium magnet rotor followed by thermal treatment for recycling. The Japan Institute of Metals and Materials. 2016;57(9): 1664-1666.

[9] Dodbiba G, Murata K, Okaya K, Fujita T. Liberation of various types of composite materials by controlled underwater explosion. Minerals Engineering. 2016;89: 63-70.

[10] Matsuo S, Jung-ah K, Murata K, Dodbiba G, Fujita T. Evaluating the practical application of underwater explosion for recycling. Resources Processing. 2011;58(2): 52-58.

[11] Murayama Koichi. Thin metal wire discharge shock crush control for concrete structure, Kakenhi-Project. 2017. https://kaken.nii.ac.jp/file/KAKENHI-PROJECT-26420448/26420448seika.pdf.

[12] Gjergi D, Fujita T, Murata K. Estimation of various wet crushing methods for construction wastes recycling. Japan Society of Material Cycles and Waste Management, 21st Annual Meeting Preprint. 2010;2-B3-7.

[13] Kasai Y. Static Expansive Demolition Agent for Rock and Concrete. 19 Concrete Journal. 1982; 20(10): 817.

[14] Toda Corporation. Low noise, low vibration, no polluted powder, short term decomposition of concrete by water freeze expansion, TODA News Release. 2017. https://www.toda.co.jp/assets/pdf/20170626_1.pdf.

[15] Mohammadreza M. Statistical case study on Schmidt hammer, ultrasonic and core compression strength tests. SANO Consulting Engineers Report, Tehran; October. 2008.

[16] Kristine A, Nathaniel T. Reliability of rebound hammer test in concrete compressive strength estimation. Journal of Advances in Agricultural \& Environmental Eng. 2014;1(2):198-202.

[17] Civiconcepts Home page, Tensile strength of concrete - Test \& Result. 2019. https://civiconcepts.com /2019/12/tensile-strength-of-concrete-test-result/.

[18] Li W, Luo Z, Long C, Wu C, Duan WH, Shah SP. Effects of nanoparticle on the dynamic behaviors of recycled aggregate concrete under impact loading. Materials and Design. 2016;112: 58-66.

[19] Petr MR, Sovjak PK. Impact testing of concrete. Proc. of the Intl. Conference on Advances in Civil: CSME. 2014: 63-67.

[20] Banthia N, Mindess S, Bentur A, Pigeon M. Impact testing of concrete using a drop-weight impact machine. Experimental Mechanics. 1989;29(1): 63-69.

[21] Nagaoka Y. Oscillation and wave. SHOKABO Co., Ltd. 2006;v14: 112-145.

(C) 2021 by the author(s). This work is licensed under a Creative Commons Attribution 4.0 International License (http://creativecommons.org/licenses/by/4.0/). Authors retain copyright of their work, with first publication rights granted to Tech Reviews Ltd. 